\title{
Robotics and Early-years STEM Education: The botSTEM Framework and Activities
}

\author{
Ileana M. Greca Dufranc ${ }^{1}$, Eva M. García Terceño 1, Marie Fridberg 2, Björn Cronquist 2, \\ Andreas Redfors ${ }^{2 *}$
}

\author{
1 Universidad de Burgos, SPAIN \\ ${ }^{2}$ Kristianstad University, SWEDEN
}

*Corresponding Author: andreas.redfors@hkr.se

Citation: Greca Dufranc, I. M., García Terceño, E. M., Fridberg, M., Cronquist, B. and Redfors, A. (2020). Robotics and Early-years STEM Education: The botSTEM Framework and Activities. European Journal of STEM Education, 5(1), 01. https://doi.org/10.20897/ejsteme/7948

Published: April 17, 2020

\begin{abstract}
botSTEM is an ERASMUS+ project aiming to raise the utilisation of inquiry-based collaborative learning and robots-enhanced education. The project outputs are specifically aimed to provide in- and pre-service teachers in Childhood and Primary Education and children four-eight years old, with research-based materials and practices that use integrated Science Technology Engineering Mathematics (STEM) and robot-based approaches, including code-learning, for enhancing scientific literacy in young children. This article presents the outputs from the botSTEM project; the didactical framework underpinning the teaching material, addressing pedagogy and content. It is a gender inclusive pedagogy that makes use of inquiry, engineering design methodology, collaborative work and robotics. The article starts with a presentation of the botSTEM toolkit with assorted teaching practices and finishes with examples of preliminary results from a qualitative analysis of implemented activities during science teaching in preschools. It turns out that despite perceived obstacles that teachers initially expressed, the analysis of the implementations indicates that the proposed STEM integrated framework, including inquiry teaching and engineering design methodologies, can be used with children as young as four years old.
\end{abstract}

Keywords: STEM, robotics, preschool

\section{INTRODUCTION}

STEM programmes are receiving increasing attention in the research literature, and decision makers are becoming interested in incorporating STEM approaches in formal education. This is because these approaches are considered efficient for developing scientific literacy for citizens and for increasing the number of young people choosing to study scientific-technological disciplines at the end of their compulsory schooling (EU, 2015; NRC, 2012, 2014). However, what can be understood as an integrated STEM approach is not clear. Nowadays, many different conceptions of curriculum integration for STEM coexist (Bybee, 2010) but only a few theoretical frameworks for teaching exist (Ortiz-Revilla et al., 2018), and the didactical guidelines are often not specific enough for teachers' implementation (Chu, Martin, and Park, 2019). Furthermore, most initiatives are addressed to teenagers, but recent research (Tytler and Osborne, 2012) points out that early childhood intervention could be very efficient. What is more, while children at elementary school often have an intrinsic interest in STEM content areas, a declining pattern in attitudes towards science has been found as the age of the students increase (Ali et al., 2013; Denessen et al., 2015; DeWitt and Archer, 2015; Said et al., 2016). Moreover, students from upper elementary 
and middle school grades show negative attitudes towards the enjoyment of science lessons (Ali et al., 2013; DeWitt and Archer, 2015). Therefore, pre-primary and primary education stages constitute great opportunity for smoothing the way, and help generate positive attitudes to STEM.

The ERASMUS+ project Robotics and STEM education for children and primary schools (botSTEM) with partners in Spain (coordinators), Sweden, Italy and Cyprus that is reported on here, has developed a didactical framework for integrated STEM activities involving robotics for preschool and primary schools (children four-eight years old.). The project outputs are specifically aimed to provide in- and pre-service teachers in Childhood and Primary Education with a didactical framework and research-based and tested robotics activities designed to scaffold STEM-teaching. This article aims to present the project output and starts of by presenting the developed theoretical framework for the botSTEM integrative STEM approach. Then the process of searching for and collecting tested robotics practices, which have been, together with the developed framework, the basis for the development of new robotics activities is described. One example of the practices developed within botSTEM is presented in Appendix A. Finally, the research framework for ongoing implementation of botSTEM activities is described with some preliminary results given from qualitative analysis of implemented activities during STEM teaching scaffolded by robotics in preschools.

\section{DIDACTICAL FRAMEWORK OF STEM AND ROBOTICS}

\section{STEM and Science}

Two main themes are prominent in the botSTEM partners' stance on the goals of science education: science as an institution of liberal democracy, and science as a discipline composed of principles and processes that need to be mastered. There is often a tension between science education aimed at producing the next generation of professional scientists (Vision I), and science education aimed at equipping citizens with the knowledge and understanding of science that they need to participate in democratic decision making (Vision II) (Roberts, 2007). Countries, school districts, schools and even individual teachers differ in the relative weight that they give to each aspect, although it seems that many standards-based movements and organizations, such as EU, OECD and NRC support a combination of the two, which is also the main goal of the botSTEM project.

botSTEM is focusing on integrative STEM (Science - Technology - Engineering - Mathematics), which is a comprehensive approach merging the different content areas through active and participative methodology involving problem-based learning and collaborative projects. The objective of this approach, considered useful for all ages, is to achieve a STEM literacy that can be summarized as

\footnotetext{
"the ability to adapt to and accept changes driven by new technology work, to anticipate the multilevel impacts of their actions, to communicate complex ideas effectively to a variety of audiences, and perhaps most importantly, to find measured, yet creative, solutions to problems that are today unimaginable" (Lederman, 1998).
}

STEM education implies a higher level of integration than the treatment of the four content areas in the acronym defined separately. STEM can be considered a new discipline uniting all the included content areas in what has been called integrated STEM education (Zollman, 2012) - a form of crosscutting educational instruction that can develop competencies among students in an integrated and humanist manner (Ortiz-Revilla et al., 2018). It is worth stressing that even though practices from all content areas are required to support STEM learning, there is often one STEM area that plays a dominant role (Honey et al., 2014). Since education in early childhood should be preferably holistic, child centred, project- and problem-based, the integration of science, technology, engineering and mathematics fields creates valuable STEM experiences for children (Kermani and Aldemir, 2015; Toma and Greca, 2017).

Integrated STEM approaches imply several challenges for teachers. Making crosscutting STEM connections is not an easy task, requiring that teachers prepare lessons that allow students to understand how STEM knowledge is applied to real-world problems. To make these connections, teachers need to address both content and pedagogy. However, identifying exactly what content and pedagogy are is often complex and difficult (Dare et al., 2019). Even in the USA, where STEM approaches have been advocated since the nineties, few teachers have operationalized STEM education (Kelley and Knowles, 2016). Perhaps, many teachers consider designing and delivering interdisciplinary and multidisciplinary lessons require too much time and effort (Chu et al., 2019).

The framework proposed by botSTEM attempts to help teachers overcome these challenges, based on five ideas presented in the following. First, it is considered that integrative STEM education is more pertinent and viable for elementary school, because teachers teach most of the subjects to the same class. In goal-directed preschool, an integrated STEM approach fits well with the didactics of early childhood education that is at present applied in the classroom. Teachers need to be carriers of both knowledge of the content and updated skills on how 
to generate situations that support the learning of their children (Fleer and Pramling, 2015; Thulin and Redfors, 2016). In the words of Fleer, "The challenge goes beyond content knowledge to teacher beliefs and pedagogy practices" (Fleer, 2009: 1074). Teachers' attitudes to the content area is important and Fleer et al. (2014) have shown that teachers have unique possibilities by implementing a 'sciencing attitude', which fits in well with integrated STEM.

Second, in terms of methodologies, although several methodologies can be useful within this approach, the framework proposed is based on inquiry and engineering design methodology. Inquiry helps intertwine the different fields in STEM through real world problems. Working with inquiry-based STEM activities provides children with opportunities to practice skills such as reasoning, reflection, questioning, modelling, justifying decisions and communicating. In this framework, guided inquiry is used, (Bevins and Price, 2016; NRC, 2012) because it seems to be the best for four-eight years old children as well as it is the model that seems to provide the best learning results (Minner, Levy, and Century, 2010). Nevertheless, in many integrated STEM education programs, engineering design practices are increasingly emphasized (Kang, 2019), since design problems are all strongly related to the everyday world. Engineering often plays a central role as an 'integrator' that helps to contextualize student learning, providing rich contexts in which learning and the application of science and mathematics concepts and practices happen when students are actively looking for solutions (Kelley and Knowles, 2016).

Both methodologies imply collaboration, an essential part of an integrative STEM approach to teaching and learning. Collaboration emphasizes joint participation in the task, intellectual interdependence, and the coconstruction of knowledge, making it difficult, and at times impossible, to identify the individual contributions in the final products. Collaboration demands careful preparation, because some students may not view peerinteraction or group work as a form of viable learning at all, but as a game. Effective communication in peer interaction also involves shared norms regarding turn taking; shared perceptions of the appropriate amount of overlap in verbal contributions and shared norms for the acceptance of different point of views, to reach consensus and make the process continue onwards. It is worth stressing that integrative STEM approaches require collaboration not only between children but also with teachers, who support the process by creating a "bridge" between the child's previous experiences and the new focus of knowledge (Thulin and Redfors, 2016).

Third, in terms of contents, it is considered that the relation between theoretical scientific models and reality is central for the scientific processes. Observations and experiments are embedded in theory and therefore "Theory laden" (Hanson, 1958). Empirical and theoretical work is connected leading to construction and refinement of theories and theoretical models in an interactive process of discussions, experiments and observations in the science community (Adúriz-Bravo, 2012; Giere, 1988; Koponen, 2007). Communicating this in science class is part of making the nature of science (Erduran and Dagher, 2014; Lederman, 2007) explicit, which has been found central for the teaching of science. botSTEM activities focus on versatile theoretical models for talking about, predicting and explaining science phenomena pertinent to the selected age group (four-eight years old). Therefore, focus in the botSTEM project is on theoretical models connected to Big Ideas (Harlen, 2015), and to the everyday lives of the selected age group. Also related with contents, the approach adopted in this project, in consonance with the definition of technological literacy, refers to learning among children of the use of the tools that scientific professionals, mathematicians and engineers, employ. In this sense, children must learn to take data with appropriate tools (scales, tape measures, dynamometers, thermometers, chronometers, microscopes, test tubes, etc.) as well as the necessary tools to analyse such data (spreadsheets) and to present them (word processors). Through these activities, children should understand how technology shapes and is shaped by society.

The fourth idea is about how computational thinking (by means of robotics and/or code learning), an aspect discussed below, is regarded as valuable for its potential to teach logical thinking, problem solving and digital competence, and should be introduced at early childhood.

The fifth and final idea builds on that, given that girls in general are more negative towards technology and its development (Bøe et al., 2011; Henriksen et al., 2016), botSTEM pursues to establish gender inclusive teaching and learning activities for early childhood. Evidence suggests that gender-balanced curricula should strive to be contextualized in line with the interests of girls, linking abstract concepts to real-life situations, and use hands-on activities (UNESCO, 2017). Hence, inquiry and engineering design methodology are potentially useful methodologies, since they emphasize the use of scientific concepts in finding solutions to real-life problems. Also, complementary strategies should be adopted by the teachers, such as encouraging the participation of girls in the communication and reviewing group work to encourage girls to adopt an active role (Scutt et al., 2013).

\section{Robotics, Computational Thinking and Coding}

Since there are few articles that address principle-based framework for teaching educational robotics concepts for early childhood (Misirli and Komis, 2014), this aspect of the proposed framework will be dealt with more extensively. botSTEM concurs with the definition found in Wikipedia for robots and robotics: 
A robot is a machine, especially one programmable by a computer, capable of carrying out a complex series of actions automatically. Robotics is an interdisciplinary branch of engineering and science that includes mechanical engineering, electrical engineering, computer science, and others. Robotics involves design, construction, operation, and use of robots, as well as computer systems for their perception, control, sensory feedback, and information processing. (Wikipedia, 2020)

Hence, integrated STEM education can be formulated in terms of robotics activities focusing on several, if not all, of the four content areas in STEM, and pertinent theoretical models of science. Robots are increasingly finding their way into classrooms, and Educational Robotics (Eguchi, 2017) is discussed as a transformational tool for learning computational thinking, coding, and engineering. According to Eguchi (2017) educational robotics is an effective learning tool for project-based learning where STEM, coding, computer thinking, and engineering skills can all be integrated in one project. Robotics provides opportunities for students to explore how technology works in real life, while giving them the opportunity to find new ways to work together to foster collaboration skills, express themselves using the technological tool, problem-solve, and think critically and innovatively. Most importantly, educational robotics provides a fun and exciting learning environment because of its hands-on nature and the integration of technology. The engaging learning environment motivates students to learn whatever skills and knowledge needed for them to accomplish their goals in order to complete the projects of their interest (Eguchi, 2017).

According to Wing (2006) computational thinking is a problem-solving skill-set rooted in computer science. The skill-set comprises solving problems, designing systems and understanding human behaviour. Computational thinking represents a type of analytical thinking, which is, according to Wing (2006), applicable to everybody, not just computer scientists. Generic skills like identifying patterns, breaking apart complex problems into smaller steps, organizing series of steps to provide solutions, etc, are put forward.

Coding is the action of putting together sequences of instructions and debugging, or problem solving and is often described as the new language of the digital society, needed to be understood by everyone in order to be able to interact in a culture and society heavily influenced by computer systems. Coding with robots shows children what they can create with technology, engaging children as producers and not merely consumers of technology (Bers, 2018). Bers (2018) suggests seven powerful ideas for early childhood computational thinking.

- Algorithms - a series of ordered steps taken in a sequence to solve a problem sequencing, such as for instance tying shoelaces. Understanding abstraction is central to understanding algorithms and its practice goes beyond computational thinking. Identifying what constitutes a step in the sequence is a matter of abstraction.

- Modularity - breaking down tasks or procedures into simpler units, engaging in decomposition. This can be practiced without computers, for instance when analysing the task of having a birthday party. What different tasks are involved? How detailed should the tasks be described? Inviting guests could for example be broken down further.

- Control structures - the order in which instructions are followed or executed. More advanced examples of control structures are repeat functions, loops, conditional events and nested structures. However, in the early childhood the key issue is familiarizing with patterns and realizing the relationship between cause and effect e.g. when you click the mouse and $\mathrm{x}$ does $\mathrm{y}$, or when the robot detects light through its light sensor and the robot should beep.

- Representation - sort and manipulate data and values in different ways. Concepts can be represented by symbols, e.g letters can represent sounds, numbers represent quantities, programming instructions represent behaviours. Different types of things have different types of attributes, e.g cats have whiskers. In addition, data types have different functionalities, e.g numbers can be added, letters can string together. To code, children need to understand that programming languages use symbols to represent actions.

- Hardware/software - computing systems need hardware and software to operate, where the software provides instructions to the hardware. Robots are mainly visible hardware but some components might be hidden, e.g. circuit boards. Children need to understand that hardware is programmed to perform a task and many devices can be programmed, not just computers.

These five powerful ideas have their origin in computer science and are all strongly linked to foundational concepts in early childhood education. However, Bers (2018) puts forward two more powerful ideas concerning processes and habits of mind; debugging and the design process.

- Design process - an iterative process used to develop programs and tangible artefacts. Bers (2018) suggests a series of steps defining a design process adapted for children, where the design process is a cycle: there is no official starting or ending point. The steps are; ask, imagine, plan, create, test and improve, share.

- Debugging - allows us to fix our programs using testing, logical thinking and problem solving. Once children understand how to debug their systems, they start to develop common troubleshooting strategies that can 
be used on a variety of computing systems. Things do not just happen to work on the first try, but many iterations are usually necessary to get it right.

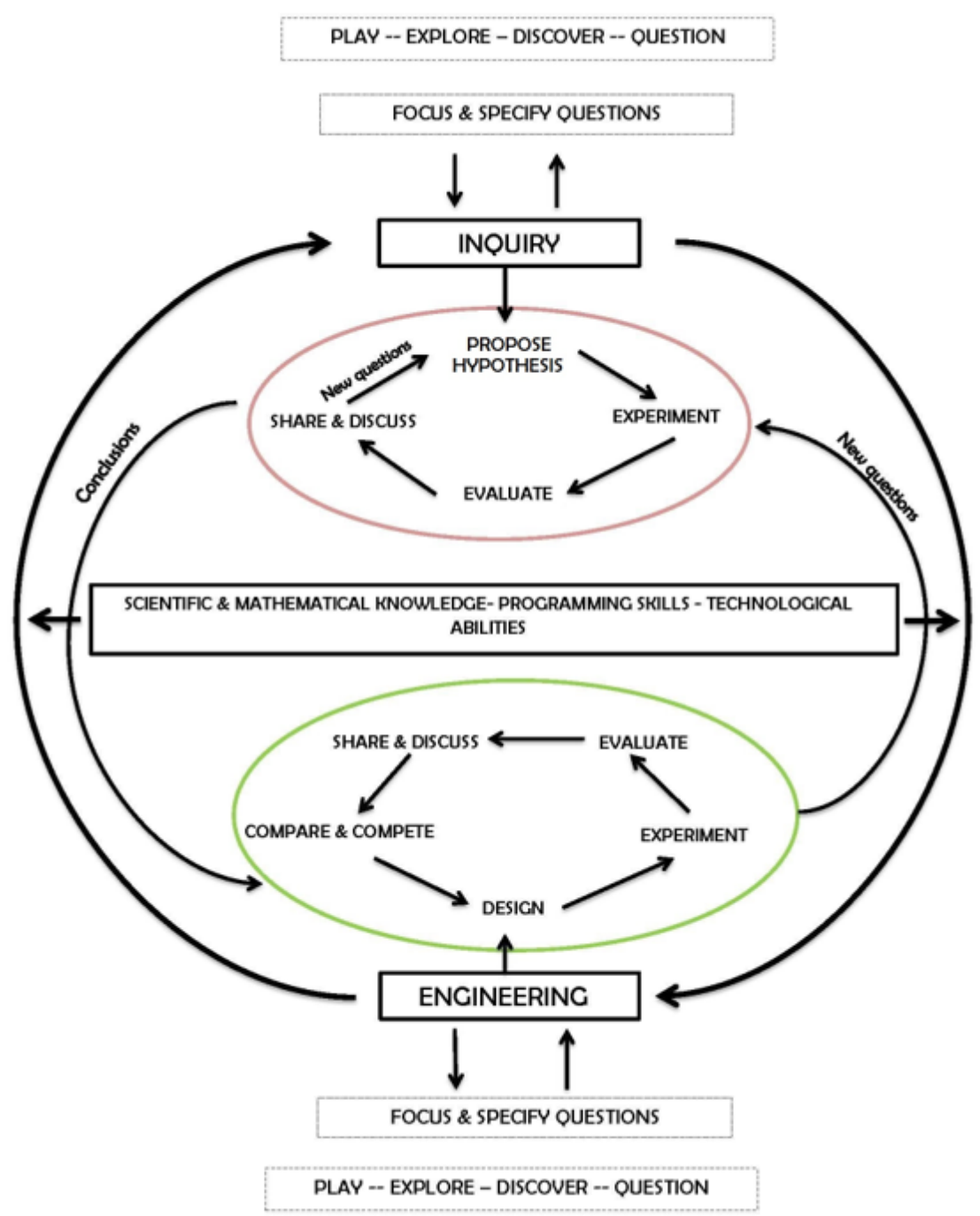

Figure 1. botSTEM didactical model developed for introducing integrated STEM education at elementary grades. Inspired by Chalufour \& Worth (2004)'s cycle of inquiry.

Summing up, the didactical framework for underpinning the didactical material addresses pedagogy and content within an integrated STEM education: a gender inclusive pedagogy that makes use of inquiry, engineering design methodology, collaborative work, robotics and a scientific content that relates to Harlen's science big ideas and coding.

\section{The Didactical Model Proposed in the botSTEM Project}

The ideas shaping the botSTEM framework have been organized in a didactical model, shown schematically in Figure 1, that makes use of inquiry teaching and engineering-design methodologies. Both methodologies imply a certain number of steps and research suggests that young children can follow both, although some adjustments must be made. Inquiry teaching and engineering design are about questions, but, as Chalufour and Worth (2004) note, it is difficult for children to ask questions about something they have neither seen, nor touched, nor experienced. These authors propose that it is very important for young children first to engage, notice, wonder and question. That is, to be given time to play in a scientifically stimulating environment. It is therefore considered necessary to create these rich environments to stimulate children's questions, as can be seen in Figure 1. These environments can be created bringing to class objects, toys or through playful activities related with the topic that is going to be addressed for children that interact with them. As many of the emergent questions may not be investigated, the role of the teacher is to focus observation and to clarify questions.

Next, our STEM model consists of three phases, each designed to encompass more than one STEM discipline. Thus, in the first phase, teachers propose an engineering-based real-world problem, based on children's observations and questions that serves as a context to teach science-related content matter. During the second 
phase students perform a guided inquiry (Martin-Hansen, 2002) in which, among other tasks, the students conduct different experiments using scientific practices and technology, in order to apprehend the knowledge necessary to solve the initial problem. The third and final phase (the problem resolution) requires the design or implementation of a technological solution for the initial problem. In this way, students begin to explore engineering design, linking engineering and science, as proposed in NRC (2012). It is worth stressing that the teacher can begin a cycle through a guided inquiry, for example, if children are curious about why oil and water do not mixture, a lava lamp can be proposed as a challenge. As appears in Figure 1, simplified steps are proposed in both methodologies. In the case of inquiry, propose hypothesis, experiment, evaluate, share and discuss. Since teachers are proposed to work with both methodologies, the conclusion step from the inquiry phase is an input of the engineering design methodology. The steps of the engineering design methodology are similar, including a compare and complete step is needed, since a relevant aspect of the engineering design methodology is to compare the different solutions achieved (in terms of efficiency, sustainability, beauty, etc). Nevertheless, the teacher can make these steps more complex, depending on the children's responsiveness. Collaboration among children and with the teachers should be actively promoted during the use of both methodologies.

Maths concepts (such as classification, order, units, symmetries, graphics) are used explicitly in all the phases. Similarly for technology, where besides the use of tools to take data, to analyse it and to present results, technology can be utilised to express children's scientific explanation models, for example by means of 'stop-motion' technique (Fridberg et al., 2017).

Related to computational thinking, a scaffolding process is proposed: begin with simple robots (that can be programmed physically), followed by the introduction to block-based coding (like $S c r a t c b^{\mathcal{O}}$, that can be used for presentations, simple modelling, etc.) and ending with physical computing (like BBC microbit, that children can programme to be used as different measuring devices). Also, robotics and programming are integrated in two different ways: as auxiliary to a science real-world problem that guides the activities, or central when the problem is directly related with robotics. In the first case, for example, robots can be used to consolidate the new knowledge, letting children program a robot to "find" answers or using simple programming tools for modelling the phenomena. In the second case, activities such as the design of a domotic garden (or 'smart garden') where robotics and programming are directly integrated with the STEM content. See appendix A for the example activity 'Domotic garden.'

Figure 1 outlines this didactical model. This combined use of both methodologies, framed in a rich environment, fosters the development of scientific and mathematical knowledge, programming skills and technological abilities.

\section{OUTPUT FROM THE botSTEM-PROJECT}

The output from the botSTEM-project presented here involves the above discussed didactical framework and a downloadable interactive Toolkit, freely available at botstem.eu. The toolkit includes practices for collaborative inquiry teaching and learning concerning robotics and STEM with methodological guidelines. The activities in the toolkit are partly from a search for successfully implemented robotics practices that pay special attention to STEM and gender perspectives, and newly developed practices by botSTEM partners. The activities have been tested and improved by teachers and results from the implementations of selected activities are presented below.

\section{The Search for Tested Practices}

Main criteria for the search for successfully implemented practices addressing four-eight years old children were:

- Pedagogical innovative strategies in education with robotics

- Generic and versatile in relation to robotics and robots

- Specific learning goals for several of the four content areas S, T, E, M

- Learning goals related to big ideas in science

- Gender inclusive

- Including collaborative work

- Involvement of a wide educational community (parents, stakeholders)

- Extended in time

A search for existing robotics practices matching the criteria listed above has been completed. The search was made through use of databases at ERIC, Springer, Routledge and Wiley and Google (Google scholar), as well as Scientix database. In addition, science education researchers and experienced 'expert' teachers were interviewed. The search gave a limited number of educational practices (47) involving more than one of the content areas in 
STEM, coupled to robotics and programming for our target ages. Most of the practices found were extracurricular practices, being developed in non-formal environments. Also, activities focusing gender inclusion and described from a gender perspective proved difficult to find for young children. However, so far discussions with experienced teachers and researchers has rendered a view among the teachers that activities involving robotics have proven to be by nature gender inclusive, and it has not been seen as a major issue, especially not for the early-years age group (four-five years old). Another discovery, also confirmed by the experienced teachers, was that, prior to botSTEM, teachers working with digitalization tended to use activities that was readily available and easy to buy and use, rather than theoretically-based teaching activities accompanied by didactical frameworks supporting the teaching.

\section{The Use of the Didactic Model for Developing New Teaching Material}

STEM integrated activities were designed based on the didactical model described above. Among the activities, issues related with magnets, changes of matter, simple machines, solutions and mixtures, plants, heat transfer and gravity, can be found, all of them addressing at least one big scientific idea and robotics/programming. These activities, along with the theoretical framework and other on-line resources constitutes the project toolkit, available through the interactive web-site of the project (www.botstem.eu). The guidelines provided in the activities have to be adapted to their specific contexts by teachers, and the site includes forums for teachers in a Moodle platform, where they can discuss experiences during implementations and share advices for future teaching.

An example of the activities developed following the didactical model, that also appears in the botSTEM toolkit, is presented in Appendix A. The activity, intended for children seven-eight years old, spins around the design of a domotic garden (or 'smart garden'), that is, the design of a garden with an automation system for irrigation. This is an example of how a "robotic" problem serves as anchor to learn about a key idea in science (in the example: organisms require a supply of energy and matter for which they often depend on, or compete with, other organisms) and to apply mathematical knowledge on measurement systems, representation of data and graphs. At the same time, children learn to programme and design an automating device. Furthermore, a possible extension of the activity - named 'how to care for plants on Mars' - allows for the introduction of astronomical concepts. The teacher initiates the activity by creation of a stimulating environment through distribution of plants with very different needs in classroom, and through videos of existing 'smart gardens.' In this way, children get the opportunity to identify and analyse advantages and disadvantages of how 'smart gardens' work, and pose questions about the different needs of the living plants. The definition of the variables that must be controlled in a 'smart garden' allows the introduction of BBC microbit and programming in order to construct a measuring tool, i.e. measuring temperature, humidity, light and so on. It is worth noting that in this part of the activity, the children are working and learning about current technology. Once the children programme the instrument, an inquiry cycle can begin, focused on the needs of the plants. For example, they can use two different plants (basil and cactus) and propose experiments to determine their optimal living conditions, such as following their development for a couple of weeks varying temperature, humidity or lightening. After sharing the results obtained, children can enter the engineering design cycle, designing a watering system for each type of plant, using the knowledge obtained through the inquiry cycle.

As can be seen in Appendix A, the outline of the activity, following the different phases of the didactical model, is given to the teachers, as well as some suggestions and hints (derived from its use with children) that might be useful for the implementation.

\section{Implementation of the Teaching Activities in Preschools}

The botSTEM activities are being implemented, evaluated and refined in preschools in Spain and Sweden during 2018-2020. A design-based implementation (Barab and Squire, 2004) of the activities, guided by variation theory (Marton and Booth, 1997; Marton, 2014) is followed. One of the basic ideas of variation theory (Marton and Booth, 1997) is that learning is always directed at something (phenomenon, object, skill, aspect of reality). This something is called the object of learning and 'learning' entails a qualitative change in the way of experiencing the object of learning - ways of acting originate from ways of experiencing (Marton, Runesson, and Tsui, 2004). There is a dynamic nature to the object of learning. The 'intended object of learning' planned by the teacher will not be the same as the 'enacted object of learning' that the teacher implements in complex classroom situations, and what the students actually experience (the 'lived object of learning') is again not the same as the enacted object of learning (Marton et al., 2004). In planning the teaching of each activity, teachers were asked to discuss with colleagues, and formulate answers about the intended object of learning (What knowledge are the children expected to develop?; What does it mean to understand this?; What differs between different ways of understanding this?; How are they expected to understand and use the knowledge afterwards?) about both STEM and robotics. Through both participative and non-participative observation, several teachers have been observed during activities, in order to 
determine the enacted and the lived object of learning. Video data of implemented activities have been collected and interviews of teachers pre and post their experience with the activities have been performed.

Preliminary results from the teaching of young children (four-six years old) in Swedish preschools (Cronquist, Fridberg, and Redfors, 2019; Fridberg and Redfors, 2020) indicate that robotics may function as a motivation factor for exploring scientific concepts. In the data, teachers and children discuss, cooperate and physically try out skills in computational thinking with the focus of helping robots to overcome obstacles. These obstacles could be created by the teacher with a specific aim, such as giving the children a task to help the robot up an inclining plane, or by the children themselves in spontaneous inquiry and play situations. Programming the robots is indicated to be a complex task for children in itself, especially when they have to program the robots to turn around. The robot activities make the children reflect about their own role in the programming. In a situation where a robot was programmed to walk up an inclined plane but failed and took another route then that intended by the programming child, the child uttered: "I would like to be in his brain to see what he thinks!". The teacher answered "It's you that program him." and this made the child reflect "But then I am his brain!". The play with robots thus gives opportunities for the children to metareflect and learn about important aspects of programming and their possibilities to affect the outcome of it. Before the implementations of botSTEM activities, not all teachers and children had had experience with robots, but teachers could adapt the activities and the didactical model to the realities of their classrooms, despite perceived obstacles that the teachers initially expressed.

In the case of an activity about magnets in Spanish schools for children four-five years old (Greca, García Terceño, Cronquist, Fridberg, and Redfors, 2019), the involved teachers did not have any knowledge about how to introduce robots in their classrooms, at the outset. However, when the teachers started the activity, they felt more and more confident to introduce new ways to use robotics with the children. The activity also includes addressing laterality, spatial orientation, sequence of movements, working memory and counting. In spite the fact that the teachers that implemented this particular activity did not consider the understanding of the proposed methodologies as an object of learning, they implemented an inquiry methodology during the process. However, engineering design methodology described in the toolkit was not part of the intended object of learning - it was not addressed in an explicit or reflective way. Nevertheless, in practice, the teachers implemented an integrated STEM approach, integrating the STEM along with robotics. The reason for this could be their holistic view of education, i.e. that teachers usually work with extended teaching projects. Additionally, all Spanish teachers, without exception, agreed that an integrated STEM approach is an exceptional way to teach STEM because it encourages children to learn and it boosts their curiosity. However, after these first implementations, the teachers are still reluctant to integrate this approach in their regular teaching practice. They perceive it as isolated occurrence, even though they note that the children's competences improved significantly.

\section{CONCLUSIONS}

Even though integrated STEM education from kindergarten to high school is being promoted by national and international stakeholders, it was difficult to find teaching material for four-eight years old children, upheld by research in science education and involving robotics. Moreover, the existing frameworks did not seem to be very useful for helping teachers to develop integrated STEM activities (Chu et al., 2019), especially for the first schooling years (Ortiz-Revilla et al., 2018). Given this scenario, the Erasmus+ project botSTEM developed a research based didactical framework for integrated STEM education and robotics for early years, with a gender inclusive pedagogy that makes use of inquiry, engineering design methodology, collaborative work and robotics focusing on STEM content that relates to big ideas in science. The didactical model was used to develop teaching material in the form of integrated STEM activities, including robotics. The botSTEM-activities, as well as the theoretical framework, the didactical model, have been translated and are available in the project-partners' languages as part of the published toolkits at the project website botstem.eu. Hence, all activities are available through the interactive website of the project. Active teachers in the partner countries also have forums in a Moodle $\mathbb{C}$ platform to discuss experiences made during implementations and future teaching.

The preliminary results of the use of the didactical model and the activities in preschool indicate that, despite the fact that many preschool teachers are not used to or trained to teach STEM content areas, integrated, by experimental means and using robotics, the teachers that are working within the botSTEM-activities seem to have adopted key aspects of the framework and successfully applied them. This shows that inquiry teaching and engineering design methodologies can be used with children as young as four years old. So, the activities developed within the didactical framework, associated with the design-based implementation seem promising and potentially useful to improve integrated STEM and robotics teaching and learning at pre and primary school. More detailed analysis of implementations is ongoing and results from the final development of the activities during 2020 will be presented via botstem.eu. 


\section{REFERENCES}

Adúriz-Bravo, A. (2012). A 'Semantic’ View of Scientific Models for Science Education. Science \& Education, 22(7), 1593-1611. https://doi.org/10.1007/s11191-011-9431-7

Ali, M. M., Yager, R. E., Hacieminoglu, E. and Caliskan, I. (2013). Changes in student attitudes regarding science when taught by teachers without experiences with a model professional development program. School Science and Mathematics, 113(3), 109-119. https://doi.org/10.1111/ssm.12008

Barab, S. A. and Squire, K. (2004). Design-based research: Putting a stake in the ground. The Journal of the Learning Sciences, 13(1), 1-14. https://doi.org/10.1207/s15327809jls1301_1

Bers, M. U., (2018). Coding as a playground: Programming and computational thinking in the early childhood classroom. New York, NY: Routledge press. https:/ / doi.org/10.4324/9781315398945

Bøe, M. V., Henriksen, E. K., Lyons, T. and Schreiner, C. (2011). Participation in Science and Technology: Young people's achievement-related choices in late modern societies. Studies in Science Education, 47(1), 37-72. https://doi.org/10.1080/03057267.2011.549621

Brown, A. L., Campione, J. C., Metz, K. K. and Ash, D. B. (1997). The Development of Science Learning Abilities in Children. In K. Härnqvist and A. Burgen (Eds.), Growing Up with Science (pp. 7-40). London: Jessica Kingsley Publishers.

Bybee, R. W. (2010) What is STEM Education? Science, 329(5995), 996-996. https://doi.org/10.1126/science.1194998

Chalufour, I. and Worth, K. (2004). Building Structures with Young Children (Young Scientist).

Chu, H.-E., Martin, S. N. and Park, J. (2019). A theoretical framework for developing an intercultural STEAM program for Australian and Korean students to enhance science teaching and learning. International Journal of Science and Mathematics Education, 17(7), 1251-1266. https://doi.org/10.1007/s10763-018-9922-y

Cronquist, B., Fridberg, M. and Redfors, A. (2019). Robotics and Early-Years Stem Education - botSTEM Framework, Toolkit, and Implemented Activities in Sweden. Poster presented at the 13th Conference of the European Science Education Research Association (ESERA), Bologna, Aug 26-30, 2019.

Dare, E. A., Ring-Whalen, E. A and Roehrig, G. H (2019). Creating a continuum of STEM models: Exploring how K-12 science teachers conceptualize STEM education. International Journal of Science Education, 41(12), 17011720. https:// doi.org/10.1080/09500693.2019.1638531

Denessen, E., Vos, N., Hasselman, F. and Louws, M. (2015). The Relationship between Primary School Teacher and Student Attitudes towards Science and Technology. Education Research International, 2015, 1-7. https://doi.org/10.1155/2015/534690

DeWitt, J. and Archer, L. (2015). Who Aspires to a Science Career? A comparison of survey responses from primary and secondary school students. International Journal of Science Education, 37(13), 2170-2192. https:// doi.org/10.1080/09500693.2015.1071899

Eguchi, A. (2014). Robotics as a learning tool for educational transformation. In Proceeding of 4th International Workshop Teacbing Robotics, Teaching with Robotics \& 5 th International Conference Robotics in Education Padova (Italy).

Erduran, S. and Dagher, R. (2014). Reconceptualizing the Nature of Science for Science Education: Scientific Knowledge, Practices and Other Family Categories. Contemporary Trends and Issues in Science Education, 43. Dordrecht: Springer Verlag.

European Union. (2015). Science Education for Responsible Citizenship. Directorate-General for Research and Innovation. Brussels.

Fleer, M. (2009). Supporting Scientific Conceptual Consciousness or Learning in 'a Roundabout Way' in Playbased Contexts. International Journal of Science Education, 31(8), 1069-1089. https://doi.org/10.1080/09500690801953161

Fleer, M. and Pramling, N. (2015). A Cultural-Historical Study of Children Learning Science. Dordrecht: Springer. https://doi.org/10.1007/978-94-017-9370-4

Fleer, M., Gomes, J. and March, S. (2014). Science learning affordances in preschool environments. Australian Journal of Early Childhood, 39(1), 38-48. https://doi.org/10.1177/183693911403900106

Fridberg, M. and Redfors, A. (2020) Preschool Teachers' role in establishing Joint Action during Children's Free Inquiry in STEM. Journal of Research in STEM Education. Online first.

Fridberg, M., Thulin S. and Redfors, A. (2017). Preschool children's Communication during Collaborative Learning of Water Phases Scaffolded by Tablets. Research in Science Education, 48(5), 1007-1026. https://doi.org/10.1007/s11165-016-9596-9

Giere, R. N. (1988). Explaining science: A cognitive approach. Minneapolis: University of Minnesota Press. https://doi.org/10.7208/chicago/9780226292038.001.0001

Greca, I. M., García Terceño, E. M., Cronquist, B., Fridberg, M. and Redfors, A. (2019). Robotics and STEM education for 4-8 y.o. children in Spanish Pre and Primary schools. Poster presented at The 13th Conference of the European Science Education Research Association (ESERA), Bologna, Aug 26-30, 2019. University of Burgos, Spain. 
Hanson, N. R. (1958). Patterns of Discovery. Cambridge: Cambridge University Press.

Harlen, W. (Ed.) (2015). Working with Big Ideas of Science Education. Trieste: IAP. http://www.ase.org.uk/documents/working-with-the-big-ideas-in-science-education/

Henriksen, E. K., Dillon, J. and Ryder, J. (Eds.). (2016). Understanding student participation and choice in science and technology education. Dordrecht, the Netherlands: Springer. https:// doi.org/10.1007/978-94-007-7793-4

Kang, N.-H. (2019). A review of the effect of integrated STEM or STEAM (science, technology, engineering, arts, and mathematics) education in South Korea. Asia-Pacific Science Education, 5(6), 1-22. https://doi.org/10.1186/s41029-019-0034-y

Kelley, T. R. and Knowles, J. G. (2016). A conceptual framework for integrated STEM education. International Journal of STEM Education, 3(11), 1-11. https://doi.org/10.1186/s40594-016-0046-z

Kermani, H. and Aldemir, J. (2015). Preparing children for success: Integrating science, math, and technology in early childhood classroom. Early Child Development and Care, 185(9), 1504-1527. https:// doi.org/10.1080/03004430.2015.1007371

Lederman, L. (1998). ARISE: American Renaissance in Science Education. Fermilab-TM-2051. Batavia, IL: Fermi National Accelerator Lab.

Lederman, N. G. (2007). Nature of Science: Past, Present, and Future. In S. K. Abell and N. G. Lederman (Eds.), Handbook of Research on Science Education (pp. 831-879).

Martin-Hansen, L. (2002). Defining inquiry. The Science Teacher, 69(2), 34-37.

Marton, F. (2014). Necessary conditions of learning. New York: Routledge. https://doi.org/10.4324/9781315816876

Marton, F. and Booth, S. (1997). Learning and awareness. Mahwah, NJ: Lawrence Erlbaum Ass.

Misirli, A. and Komis, V. (2014). Robotics and programming concepts in early childhood education: a conceptual framework for designing educational scenarios Anastasia. In Research on E-Learning and ICT in Education. New York: Springer. https://doi.org/10.1007/978-1-4614-6501-0_8

National Research Council. (2012). A framework, for K-12 science education: practices, crosscutting concepts, and core ideas. Washington, DC: The National Academies Press.

National Research Council. (2014). STEM Integration in K-12 education. Status, prospects, and an agenda for research. Washington, DC: The National Academies Press.

Ortiz-Revilla, J., Greca, I. M. and Arriassecq, I. (2018). Construcción de un marco teórico para el enfoque STEAM en la Educación Primaria. En C. Martínez Losada y S. García Barros (Eds.), 28 Encuentros de Didáctica de las Ciencias Experimentales. Iluminando el cambio educativo (pp. 823-828). A Coruña, Spain: Universidade da Coruña.

Roberts, D. A. (2007). Scientific literacy/science literacy. In S. K. Abell and N. G. Lederman (Eds.), Handbook of research on science education (pp. 729-780). Mahwah: Lawrence Erlbaum Associates.

Scutt, H. I., Gilmartin, S. K., Sheppard, S. and Brunhaver, S. (2013). Research-informed practices for inclusive science, technology, engineering, and math (STEM) classrooms: Strategies for educators to close the gender gap. Proceedings of the American Society for Engineering Education Annual Conference and Exposition, June 23-26, Atlanta.

Thulin, S. and Redfors, A. (2017). Student Preschool Teachers' Experiences of Science and its Role in Preschool. Early Childhood Education Journal, 45(4), 509-520. https://doi.org/10.1007/s10643-016-0783-0

Toma, R. B. and Greca, I. M. (2018). The Effect of Integrative STEM Instruction on Elementary Students' Attitudes toward Science. Eurasia Journal of Mathematics, Science and Technology Education, 14(4), 1383-1395. https://doi.org/10.29333/ejmste/83676

Tytler, R. and Osborne, J. (2012). Student attitudes and aspirations towards science. In Second international handbook of science education (pp. 597-625). Netherlands: Springer. https:// doi.org/10.1007/978-1-4020-9041-7_41

Wikipedia (2020). Available at: https://en.wikipedia.org/ (Accessed 26 March, 2020)

Wing, J. M. (2006). Computational thinking. Communications of the ACM, 49(3), 33-35. https:/ / doi.org/10.1145/1118178.1118215

Zollman, A. (2012). Learning for STEM literacy: STEM literacy for learning. School Science and Mathematics, 112(1), 12-19. https://doi.org/10.1111/j.1949-8594.2012.00101.x 


\section{APPENDIX A: AN EXAMPLE OF A DEVELOPED ACTIVITY}

\section{Domotic Garden}

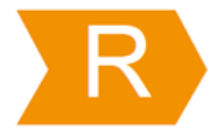

ROBOTICS

Program a

watering system for
garden

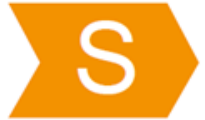

THE SCIENTIFIC METHOD

Plants - Living beings!

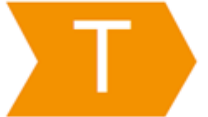

TECHNOLOGY

$B B C$ microbit

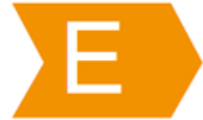

THE ENGINEERING PROCESS

Create a watering system

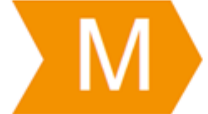

MATHEMATICS

Measurement units, tables, graphs

\section{Concise Description}

Nowadays, robots are part of our daily lives. Not only are they in industry but they are also in our houses and schools and they make our life easier. In this unit, kids are called to design and build a 'domotic garden' to grow plants in a more effectively and efficiently way. For that reason, they have to learn about what a domotic system is; how it works and how it can be programmed. In addition, they have to generate their own knowledge about plants following the Scientific Method and how to create a system capable of taking care of our garden. In order to achieve these goals, kids have to apply mathematical knowledge about measurement instruments and units, tables and graphs.

\section{Observe \& Question}

At the beginning of the class it is important to encourage a collaborative environment where kids can share their opinions and doubts, where they can work together and where they can generate their own knowledge. For that, it would be a good idea to introduce the concept of 'smart garden' through a piece of news or a video where they can analyze how it works and identify which are the advantages and disadvantages of its use. Boost a dialogue among the members of the class, what do you think about smart gardens? Is it useful? What for? What things/variables can be controlled in your garden with this system? How does it work? Is it related to robots?

Inspire children to talk and discuss more deeply about the variables which must be controlled in a garden such as temperature, humidity, insects, soil, etc. and focus their attention on two of them: temperature and humidity. Help them relate these concepts to their experiences through the evaporation process. What happens to the puddles after raining when the sun shines and the temperature is high? And if there is no sun and the temperature is low?

Introduce a discussion about their experiences and ideas about temperature and evaporation, and talk about how temperature and humidity can be measured. Make sure that the students have understood these concepts properly and then show them a BBC microbit.

\section{Play \& Discover about BBC microbit}

Let pupils investigate in groups about what a $\mathrm{BBC}$ microbit is, discover how it works and test it. After that, design some activities/challenges to work with this gadget having in mind their previous experiences with programming and specifically with BBC microbit. You can get ideas at: https://microbit.org/

When children feel comfortable working with BBC microbit, guide them in programming a temperature and a humidity gadget. If you consider it appropriate every group can be responsible of only one of them in order to explain to the other groups how they have managed to program it afterwards. Letting the pupils become a "teacher" helps them to consolidate their knowledge and improve their reasoning skills through giving and receiving instructions with peers.

\section{Design, Experiment \& Programme}

Once the $\mathrm{BBC}$ microbits are programmed it is time to test them. Create bigger groups getting together one which was responsible for a temperature gadget and other for a humidity one and give them two plants with very different needs, such as a cactus and basil.

Encourage children to identify what the plants need to live and use the Scientific Method for it. Firstly, provide them with resources that they can use to find out information about this topic that allows them to define the hypothesis, how much water does the cactus need to live? And the basil? Are high temperatures appropriate for the basil? And for the cactus? 
After that, with your support, they must design an experiment to check what conditions of temperature and humidity that these two plants need. They must decide how much water they will use for the plants and where they will be located (both plants of each group must be under the same conditions and these conditions must be different from the rest of the groups in order to compare the results afterwards). One more option to consider is to introduce the concept of sunshine, a new variable which can be measured after programming a BBC microbit as a light sensor.

During a week they have to measure the temperature and the humidity of the plants and describe how they are (students can also take photos or draw pictures), have the plants changed their colour or their size? If it has leaves, are they fresh or dry? If it has prickles, are they sharp? Does it have any shrunken part? If you consider it appropriate you can create a poster where kids can write down their results or draw graphics and tables. This will help them compare more easily the results gathered from every group.

After a week the groups must explain their findings to the rest of the class and discuss all together the analyses, the results and draw conclusions. Do both plants need the same quantity of water? Do both plants withstand cold temperatures? What happens to basils when the temperature is high?

A wide range of options can be also included in this inquiry sequence if you consider it applicable for your pupils, such as deciduous and evergreen plants, sunshine and photosynthesis or even the evolution of the plants.

\section{Engineering Design Process}

When they have defined the best conditions of temperature and humidity for the plants, each group has to choose one to take care of and design a watering system using the Engineering Design Process. Support kids to imagine possible solutions having in mind the knowledge acquired and the gadgets used before and they can analyse the ideas and suggestions proposed so as to choose the most promising one. Provide them the appropriate support to plan how they are going to create the watering system using the plants, the BBC microbit, the water sensors, the pumps and the bowls with water supply and taking into account children coding skills, help them to think and reason how to create the code asking them questions and explaining them each step. Here you have a code for your BBC microbit, but remember: there are a lot of possibilities; this is just an option.

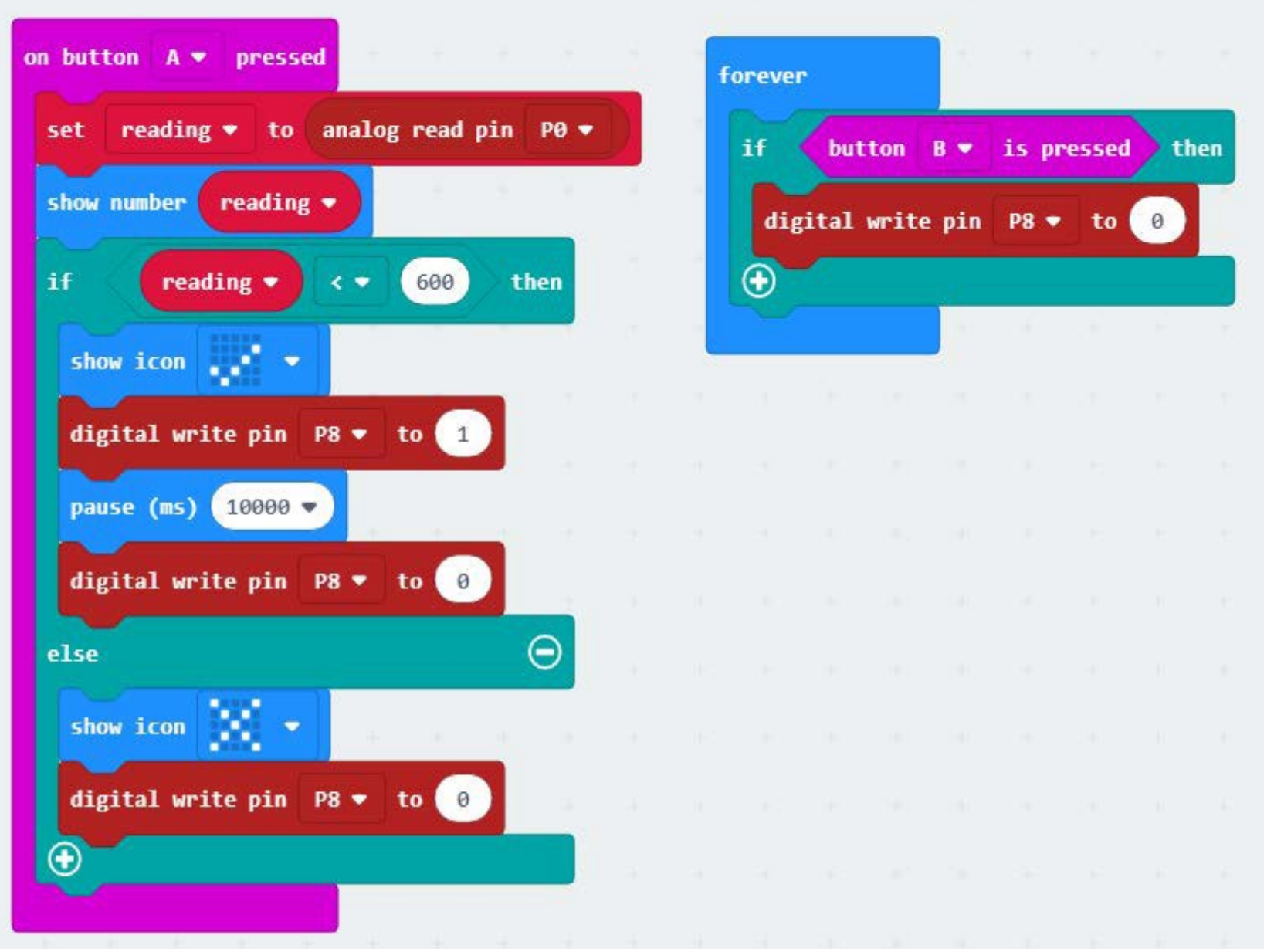

You can find some videos at: https://www.youtube.com/watch?v=jcc5Qae2Cfs 


\section{Evaluate \& Share}

Once the watering system is ready it is time to test it and make the suitable improvements. After sharing their knowledge and the key of their prototypes, a discussion can be held, is an irrigation system useful? How it can facilitate people's life? Which other applications does it have? Do these watering systems help preserve natural resources such as water? They can also create a poster, a stop motion video or a slide-presentation that shows with photos, pictures, etc., what are the best conditions for the plant they chose, what happens to the plant when the circumstances are not the right ones and how a watering system can be created.

As a complementary activity you can explore and search what are the cares that the plants would need if they were on Mars and think about how they can grow and take care of them using robots. 